\title{
Effect of power ultrasonic on solidification microstructure of Al-Ni-Zn-Mg aluminum alloy \\ Zhiwen Shao ${ }^{1, a^{*}}$, Yongdong $\mathrm{Xu}^{1}$, Yu Zeng ${ }^{1}$ and Xiurong Zhu ${ }^{1}$
}

\author{
${ }^{1}$ Ningbo Branch of China Ordnance Academy; Ningbo, Zhejiang 315103, P.R. China \\ alourry@163.com
}

\begin{abstract}
Keywords: Aluminum alloy; ultrasonic; microstructure; $\mathrm{Al}_{3} \mathrm{Ni}$.
\end{abstract}
Abstract. The effect of power ultrasonic on the solidification microstructure of a newly developed Al-Ni-Zn-Mg aluminum alloy has been investigated. The melt of the alloy was treated by ultrasonic field with different powers from $0 \mathrm{~W}$ to $850 \mathrm{~W}$. Without high-energy ultrasonic treatment, the eutectic $\mathrm{Al}_{3} \mathrm{Ni}$ phases with coarse long dendritic-shape were observed in the aluminum matrix, and its size could be much more than $50 \mu \mathrm{m}$. With the ultrasonic field of power more than $450 \mathrm{~W}$ introducing into the melt, the morphologies of the $\mathrm{Al}_{3} \mathrm{Ni}$ phases were changed into short rod-shape or particle-shape and the distributions were nearly uniform. Meanwhile, the influence of ultrasonic treating time and ultrasonic treating temperature on the morphologies of the $\mathrm{Al}_{3} \mathrm{Ni}$ phases was studied. The results showed that ultrasonic treatment of the proper time such as 180s for the Al-Ni-Zn-Mg alloy could result in considerable improvement of the morphologies of the $\mathrm{Al}_{3} \mathrm{Ni}$ phases. The morphologies and the size of the eutectic $\mathrm{Al}_{3} \mathrm{Ni}$ phases were gradually improved with the increase of temperature from $680^{\circ} \mathrm{C}$ to $760^{\circ} \mathrm{C}$.

\section{Introduction}

Due to their excellent specific strength, corrosion resistance, and relatively low labor intensity of production, high strength cast aluminum alloys were widely used in transportation sectors of automotive, aerospace, marine and railroad. Studies of high strength cast aluminum alloys mainly focused on the series of Al-Si alloys and Al-Cu alloys[1]. Al-Si alloys were endowed with excellent castability and poor strength. Meanwhile, Al-Cu alloys were possessed with high strength and unsatisfied castability. For instance, the typical high strength cast aluminum alloy ZL205A, which was named by Chinese national norm, was a cast $\mathrm{Al}-\mathrm{Cu}-\mathrm{Mn}-\mathrm{Ti}$ aluminum alloy with primary alloying elements including 4.6-5.3 wt.\% Cu, 0.3-0.5 wt.\% Mn, 0.15-0.35 wt.\% Ti and other minim elements such as $\mathrm{Zr}, \mathrm{Cd}, \mathrm{V}$ and B with their total content of $0.2 \mathrm{wt} . \%$. The tensile strength of ZL205A alloy could be about $510 \mathrm{MPa}$, but the alloy has poor casting fluidity and tendencies of casting defects including shrinkage porosity, alumina skins, entrapped air bubbles, cold fills, casting over-burnt microstructure and the dross or intermetallic inclusions[2].

Recently, V.S. Zolotorevsky et.al. [3] reported a novel high strength cast aluminum alloy Al-Ni-Zn, which was simultaneously possessing good castability and excellent high strength. The tensile strength of the Al-4.5Ni-6Zn-2Mg-Cu alloy could be more than $550 \mathrm{MPa}$, while the alloy has good casting fluidity because of the narrow solidification range and eutectic reaction $\mathrm{L} \rightarrow(\mathrm{Al})+\mathrm{Al}_{3} \mathrm{Ni}$. However, similar to the eutectic $\mathrm{Si}$ phases in the $\mathrm{Al}-\mathrm{Si}$ alloy, the coarse needle-like $\mathrm{Al}_{3} \mathrm{Ni}$ phases in the $\mathrm{Al}-\mathrm{Ni}-\mathrm{Zn}-\mathrm{Mg}$ alloy were also very easily resulting into decrease of the mechanical properties of the alloy. It has been reported that ultrasonic vibration could effectively modify eutectic silicon phases in Al-Si alloys. X. Jian et.al. [4] studied the effect of ultrasonic vibration on the eutectic silicon phases in A356 alloy, and the results showed that ultrasonic vibration can effectively convert coarse acicular plate-like shape to a finely dispersed rosette-like shape. S.L. Zhang et.al. [5] reported that due to the ultrasonic treatment, the long dendritic silicon phases in A356 alloy were broken into pieces, the distribution of the silicon phase was approximately uniform and considerable improvement of mechanical properties could be achieved. In this study, the effect of power ultrasonic on the solidification microstructure of the newly developed Al-Ni-Zn-Mg alloy was investigated and the 
influence of different conditions of ultrasonic field on the improvement in the morphologies of the $\mathrm{Al}_{3} \mathrm{Ni}$ phases was also discussed.

\section{Experimental details}

The composition (wt.\%) of the alloy used in the test was as follows: $\mathrm{Zn}, 5.90 ; \mathrm{Ni}, 3.68 ; \mathrm{Mg}, 2.13$; $\mathrm{Cu}, 0.94 ; \mathrm{Mn}, 0.27 ; \mathrm{Cr}, 0.18 ; \mathrm{Ti}, 0.06$ and balance Al. The tested alloy was prepared using Al-20\%Ni, $\mathrm{Al}-50 \% \mathrm{Cu}, \mathrm{Al}-10 \% \mathrm{Mn}, \mathrm{Al}-5 \% \mathrm{Cr}, \mathrm{Al}-\mathrm{Ti}-\mathrm{B}$ grain refiner, pure $\mathrm{Zn}$ and pure $\mathrm{Al}$ in a graphite crucible.

As shown in Fig.1, the experimental apparatus for ultrasonic treatment used in this study consisted of a resistant furnace, a graphite crucible and a metallurgic ultrasonic system with the power ranging from 0 to $2 \mathrm{~kW}$, which includes an ultrasonic generator with the frequency of $20 \pm 2 \mathrm{kHz}$, a magnetostrictive transducer, and a titanium made acoustic radiator. During the ultrasonic treatment procedure, the ultrasonic power, the temperature of the melt and the time of applying the ultrasonic field were precisely controlled. Firstly, the melting of the Al-Ni-Zn-Mg alloy was carried out in the graphite crucible which was heated by a laboratory resistance furnace. The melt was heated to $700^{\circ} \mathrm{C}$ and controlled at this temperature for $600 \mathrm{~s}$. Then, the preheated ultrasonic radiator was inserted $2 \mathrm{~cm}$ under the surface in the aluminum alloy melt and the aluminum alloy melt was treated by ultrasonic vibration. The treated melt was cast into a water-cooled copper mold, as shown in Fig1. For comparison reasons, samples were also made without ultrasonic vibration. For convenience, without ultrasonic treatment was defined as ultrasonic treatment of $0 \mathrm{~W}$. After the cast alloy was cooled, the samples taken from the same position were used for analyzing and testing. Optical microscopy was used to examine the microstructure of the samples.
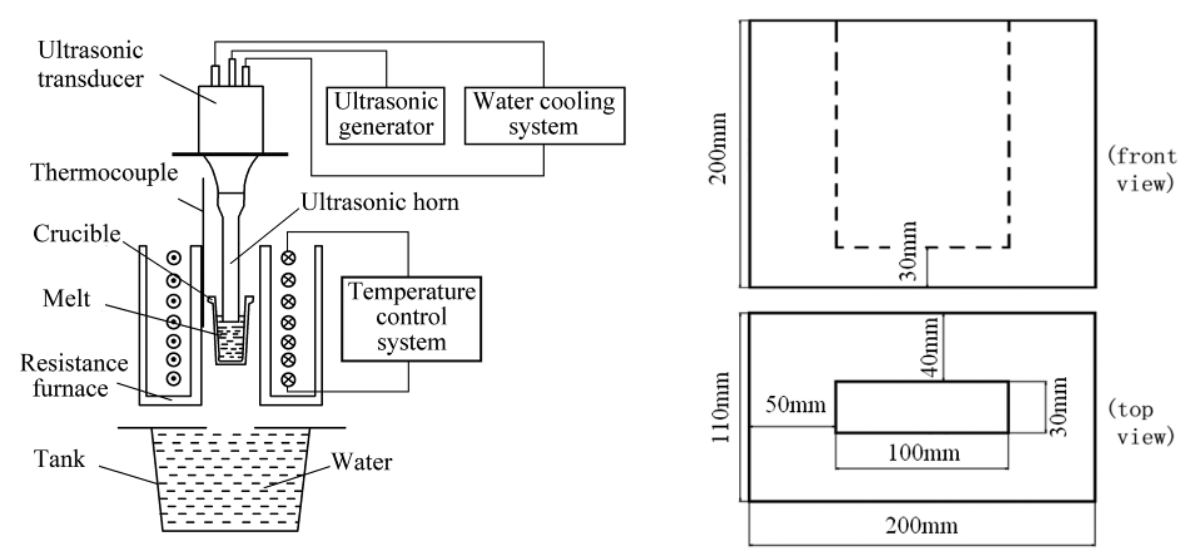

Fig.1 Schematic of ultrasonic treatment equipment for aluminum alloy melt and the water-cooled copper mould used in the experiment.

\section{Results and discussions}

Fig. 2 showed the microstructure of the Al-Ni-Zn-Mg alloy treated by ultrasonic field with different powers. It could be clearly seen that the microstructure of the Al-Ni-Zn-Mg alloy was changed with the increase of ultrasonic power. Without high-energy ultrasonic treatment, the eutectic $\mathrm{Al}_{3} \mathrm{Ni}$ phases with coarse long dendritic-shape were observed in the aluminum matrix, and its size could be much more than $50 \mu \mathrm{m}$. With the ultrasonic field introducing into the aluminum melt, the morphologies and the size of the $\alpha$-Al phases and eutectic $\mathrm{Al}_{3} \mathrm{Ni}$ phases were improved. Meanwhile, the long and coarse dendritic-shaped $\mathrm{Al}_{3} \mathrm{Ni}$ phases were shortened and refined. Especially, when the ultrasonic power was more than $450 \mathrm{~W}$, the morphologies of the $\mathrm{Al}_{3} \mathrm{Ni}$ phases were of short rod-shape or particle-shape and the distributions were nearly uniform. 

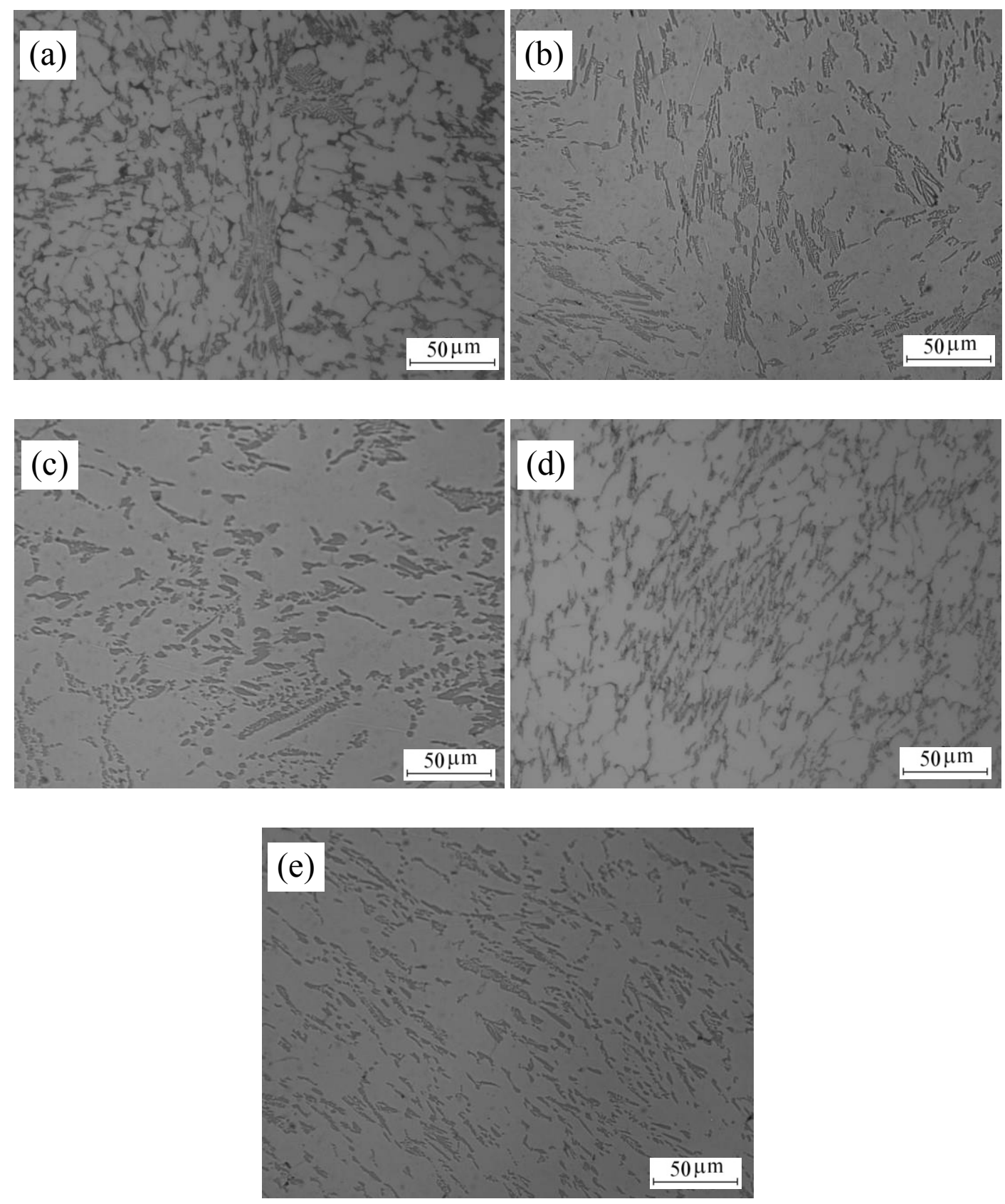

Fig.2 Microstructure of the Al-Ni-Zn-Mg alloy treated by ultrasonic field with different power.

(a) $0 \mathrm{~W}$, (b) $300 \mathrm{~W}$, (c) $450 \mathrm{~W}$, (d) $650 \mathrm{~W}$ and (e) $850 \mathrm{~W}$.

The effect of ultrasonic treatment on the microstructures of the aluminum alloy was due to the cavitation effects and acoustic streaming effects induced by the high-energy ultrasonic field [6-9]. As the ultrasonic field was introduced into the melt and the acoustic pressure exceeded the cavitation threshold, the most important effect "ultrasonic cavitation" was generated. In the other words, ultrasonic cavitation only occurred when the acoustic pressure exceeded the cavitation threshold. With the increase of acoustic pressure, the ultrasonic cavitation would be accordingly intensified [10]. Thus, it could be understood that a greater ultrasonic power which was more than $450 \mathrm{~W}$ had a better effect of microstructure improvement, as shown in Fig.2.

Fig. 3 showed the microstructure of the Al-Ni-Zn-Mg alloy treated by ultrasonic field with $650 \mathrm{~W}$ for different time. With the increase of ultrasonic treatment time, the microstructure of the Al-Ni-Zn-Mg alloy was changed. When the alloy was treated by ultrasonic for $45 \mathrm{~s}$, the eutectic $\mathrm{Al}_{3} \mathrm{Ni}$ phases with coarse dendritic-shape could still be found in the aluminum matrix, and its size could be more than $50 \mu \mathrm{m}$. With the increase of ultrasonic treatment time into $90 \mathrm{~s}, 180 \mathrm{~s}$ and $360 \mathrm{~s}$, the morphologies and the size of the eutectic $\mathrm{Al}_{3} \mathrm{Ni}$ phases were obviously improved. Especially, when the alloy was treated by ultrasonic for $180 \mathrm{~s}$, the long and coarse dendritic-shaped $\mathrm{Al}_{3} \mathrm{Ni}$ phases nearly 
disappeared. Furthermore, the morphologies of the $\mathrm{Al}_{3} \mathrm{Ni}$ phases were of short particle-shape and the distributions are nearly uniform. The results indicated that ultrasonic treatment of the proper time such as 180 s for the Al-Ni-Zn-Mg alloy could result in considerable microstructure improvement.
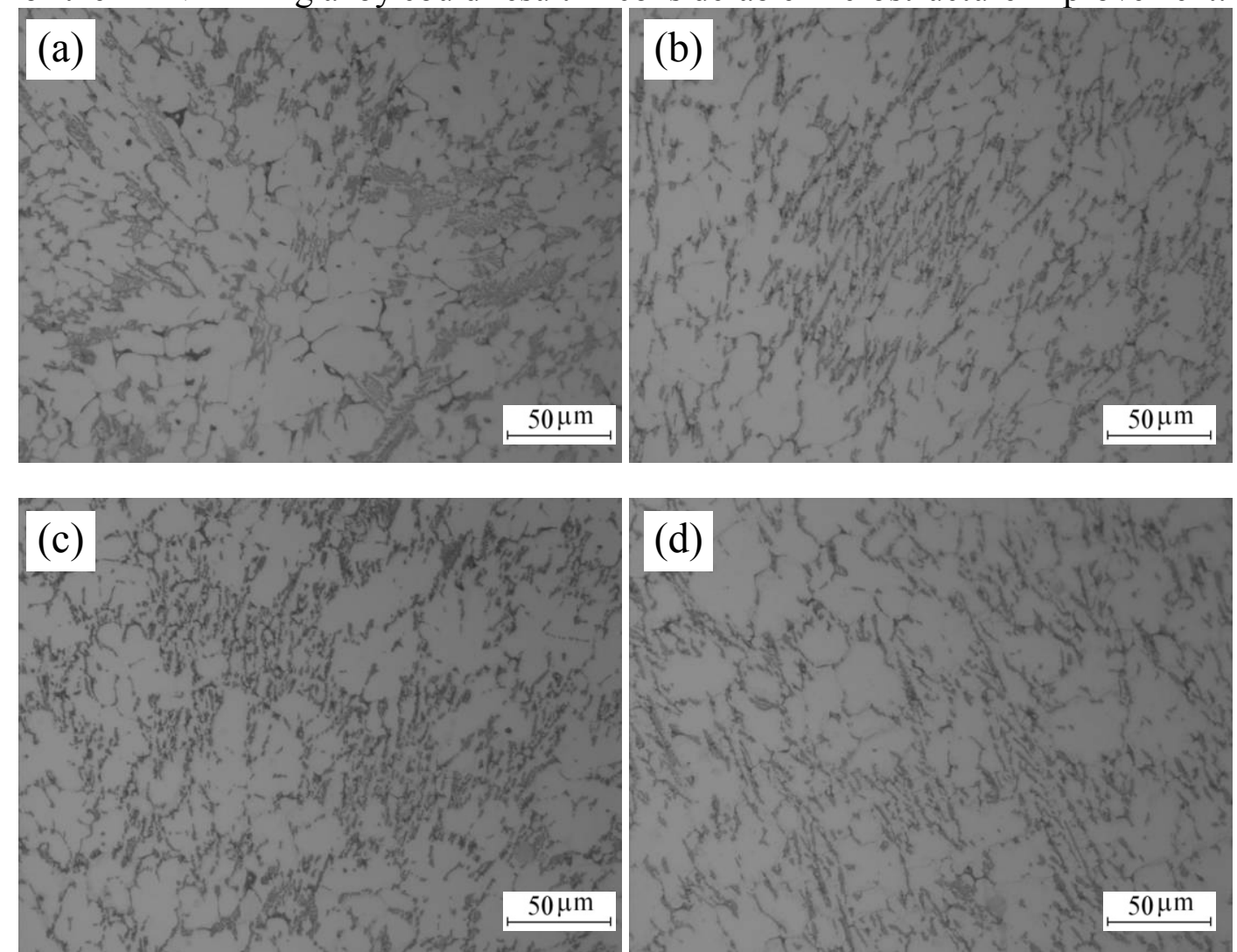

Fig.3 Microstructure of the Al-Ni-Zn-Mg alloy treated by ultrasonic field for different time.

(a) $45 \mathrm{~s}$, (b) $90 \mathrm{~s}$, (c) $180 \mathrm{~s}$, and (d) $360 \mathrm{~s}$.

The microstructure of the Al-Ni-Zn-Mg alloy treated by ultrasonic field at different temperature was shown in Fig.4. With the increase of ultrasonic treatment temperature, the microstructure of the $\mathrm{Al}-\mathrm{Ni}-\mathrm{Zn}-\mathrm{Mg}$ alloy was changed. When the alloy was treated by ultrasonic at $680^{\circ} \mathrm{C}$, the eutectic $\mathrm{Al}_{3} \mathrm{Ni}$ phases with sharply long dendritic-shape could be seen in the aluminum matrix. With the increase of ultrasonic treatment temperature into $700^{\circ} \mathrm{C}, 720^{\circ} \mathrm{C}, 740^{\circ} \mathrm{C}$ and $760^{\circ} \mathrm{C}$, the morphologies and the size of the eutectic $\mathrm{Al}_{3} \mathrm{Ni}$ phases were gradually improved. Especially, when the alloy was treated by ultrasonic at $760^{\circ} \mathrm{C}$, the long and coarse dendritic-shaped $\mathrm{Al}_{3} \mathrm{Ni}$ phases was disappeared. Besides, the morphologies of the $\mathrm{Al}_{3} \mathrm{Ni}$ phases were of refined particle-shape and the distributions were nearly uniform. 

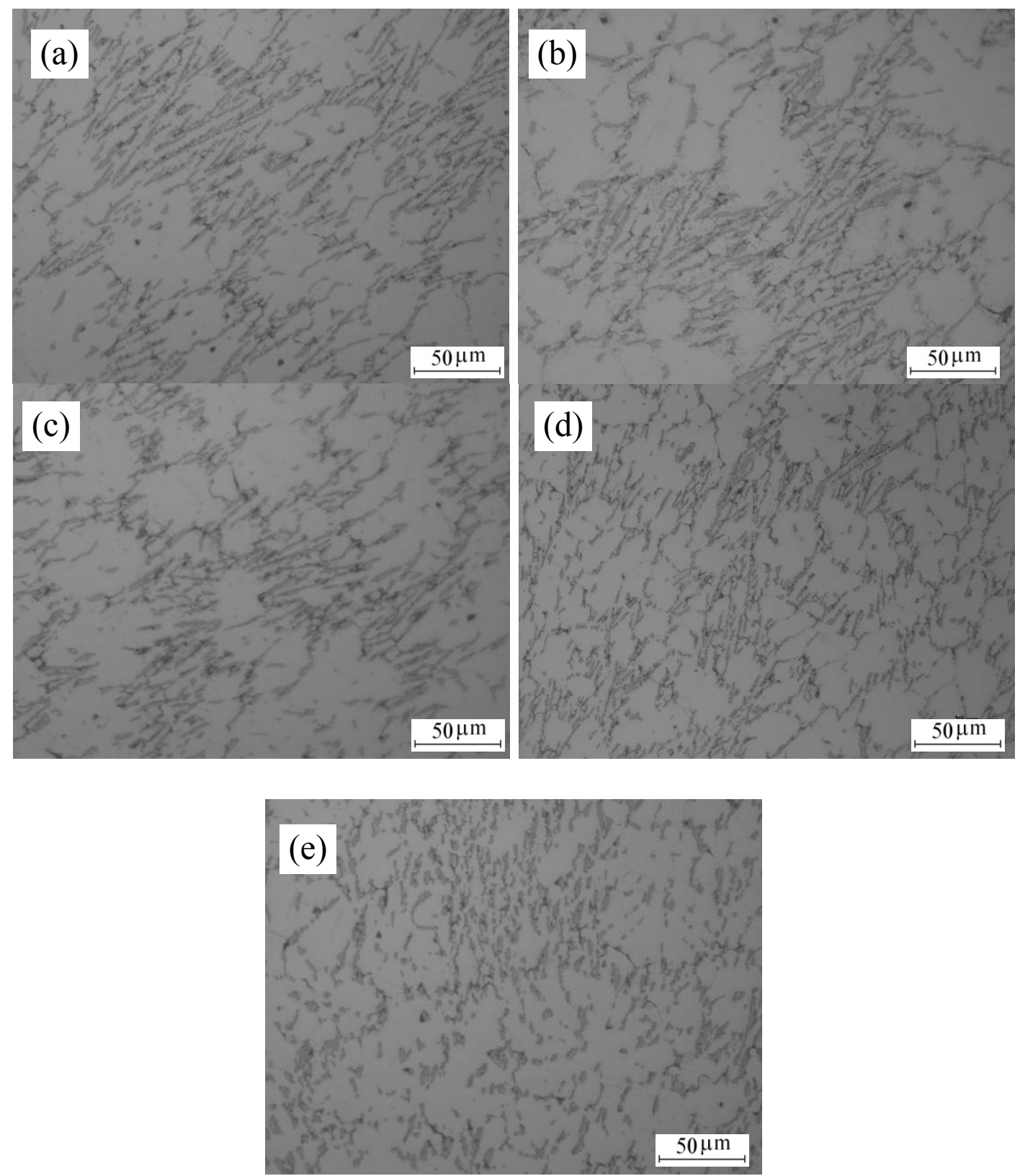

Fig.4 Microstructure of the Al-Ni-Zn-Mg alloy treated by ultrasonic field at different temperature. (a) $680^{\circ} \mathrm{C},(\mathrm{b}) 700^{\circ} \mathrm{C},(\mathrm{c}) 720^{\circ} \mathrm{C}$ and $(\mathrm{d}) 740^{\circ} \mathrm{C}$.

The main mechanisms of microstructure improvement of light alloys induced by ultrasonic treatment were based on cavitation, including cavitation-enhanced nucleation and cavitation-induced (shock waves) dendrite fragmentation [11-13]. In this study, ultrasonic treatment and microstructure improvement were obtained at $680^{\circ} \mathrm{C} \sim 760^{\circ} \mathrm{C}$, which was about $60^{\circ} \mathrm{C} \sim 140^{\circ} \mathrm{C}$ above the measured liquidus temperature of the alloy. Few grains or second phases were expected to form at such high temperature. Therefore, the fragmentation effects of cavitation and acoustic streaming phenomena were not expected to be contributing factors to the microstructure improvement. The changes brought about by ultrasonic treatment in the microstructures of the alloy were thought to be mostly related to the effects of ultrasonic cavitation on the cleaning the surfaces of the poorly wetted particles in the melt, thereby enhancing their nucleation potency $[14,15]$. Furthermore, disintegration and distribution of the agglomerated nucleant particles existing in the melt under the effects of cavitation and acoustic streaming also increased the number of effective nucleation sites. Increased density of the active nuclei in the melt resulted in the microstructure improvement of the alloy. 


\section{Summary}

The microstructure evolution of the newly developed Al-Zn-Ni-Mg alloy with ultrasonic treatment was studied. The noticeable results were listed below:

1) Without ultrasonic treatment, the eutectic $\mathrm{Al}_{3} \mathrm{Ni}$ phases of the alloy were coarse and long dendritic-shape. With the ultrasonic field of power more than $450 \mathrm{~W}$ introducing into the melt of the alloy, the morphologies of the $\mathrm{Al}_{3} \mathrm{Ni}$ phases were changed into short rod-shape or even particle-shape. Besides, the distributions were nearly uniform.

2) The ultrasonic treatment of the proper time such as 180 s for the Al-Ni-Zn-Mg alloy could result in considerable improvement in the morphologies of the $\mathrm{Al}_{3} \mathrm{Ni}$ phases.

3) With the increase of ultrasonic treating temperature from $680^{\circ} \mathrm{C}$ to $760^{\circ} \mathrm{C}$, the morphologies of the eutectic $\mathrm{Al}_{3} \mathrm{Ni}$ phases were improved gradually.

\section{Acknowledgements}

This work is financially supported by Public Technology Research Project of Zhejiang Province, China (2014C31124) and Natural Science Foundation of Ningbo City, China (201401A6105117).

\section{References}

[1] G.F. Mi , K.F. Wang , H.J. Gong, et al, Microstructure and properties of ZL205Alloy, China Foundry. 5 (2008) 24-25.

[2] B. Li, Y.F.Shen, W.Y. Hu, Casting defects induced fatigue damage in aircraft frames of ZL205A aluminum alloy-A failure analysis, Mater. Des. 32(2011) 2570-2582.

[3] V.S. Zolotorevsky ,N.A. Belov ,M.V. Glazoff, Casting aluminum alloys, Elsevier, Moscow, 2007.

[4] X. Jian , H. Xu , T.T. Meek , et al, Effect of power ultrasound on solidification of aluminum A356 alloy, Mater. Lett. 59 (2005) 190-193.

[5] S.L. Zhang, Y.T. Zhao, X.N. Cheng, et al, High-energy ultrasonic field effects on the microstructure and mechanical behaviors of A356 alloy, J. Alloys Compd. 470 (2009) 168-172.

[6] G.I. Eskin, Broad prospects for commercial application of the ultrasonic (cavitation) melt treatment of light alloys, Ultrason. Sonochem. 8 (2001) 319-325.

[7] G.I. Eskin. Powerful ultrasound applied to aluminium alloy melting and casting processes, Aluminium. 4 (2008) 79-85.

[8] T.V. Atamanenko , D. G. Eskin , L. Zhang, et al, Criteria of Grain Refinement Induced by Ultrasonic Melt Treatment of Aluminum Alloys Containing Zr and Ti, Metall. Mater. Trans. A. 41 (2010) 2056-2066.

[9] Z.T. Zhang, T.j. Li, H.Y. Yue, et al. Study on the preparation of Al-Si functionally graded materials using power ultrasonic field, Mater. Des. 30 (2009) 851-856.

[10] Z.W. Shao, Q.C. Le, Z.Q. Zhang, et al, Effect of ultrasonic power on grain refinement and purification processing of AZ80 alloy by ultrasonic treatment, Met. Mater. Inter. 18 (2011) 209-215.

[11] G.I. Eskin ,D.G. Eskin, Ultrasonic Treatment of Light Alloy Melts, Taylor \& Francis Group, Boca Raton, 2015. 
[12] G. Zhong, S.S. Wu, H.W. Jiang, et al, Effects of ultrasonic vibration on the iron-containing intermetallic compounds of high silicon aluminum alloy with 2\%Fe, J. Alloys Compd. 492 (2010) 482-487.

[13] X. Jian, T.T. Meek, Q. Han, Refinement of eutectic silicion phase of aluminum A356 alloy using high-intensity ultrasonic vibration, Scripta Mater. 54 (2006) 893-896.

[14] M. Khosro-aghayani, B.Niroumand, Effects of ultrasonic treatment on microstructure and tensile strength of AZ91 magnesium alloy, J. Alloys Compd. 509 (2011) 114-122.

[15] Z.W. Liu, Q.Y. Han, J.G. Li, Ultrasound assisted in situ technique for the synthesis of particulate reinforced aluminum matrix composites, Composites Part B. 42 (2011) 2080-2084. 